\title{
Trivial pursuit? Interpreting San rock art in terms of the mystical bond between hunter and prey
}

\author{
Dr Jean-Marie Dederen \\ University of Venda, South Africa \\ Email: Dederenj@univen.ac.za \\ https://orcid.org/0000-0003-4016-2939 \\ Ms Jennifer Munyai \\ Chris Hani House Museum, South Africa \\ Email: Jennifer.Mokakabye@ekurhuleni.gov.za \\ DOI: https://doi.org/10.46222/pharosjot.102.18
}

\begin{abstract}
For more than three decades now, researchers supporting the mainstream theoretical orientation in the field of rock art studies, the shamanistic model, have largely ignored the possibility that the idiom of the hunt could contribute meaningfully to the task of deciphering the often complex and enigmatic masterpieces of the San hunter-gatherers. They may have been mistaken all along. This paper argues that a good deal of the art produced by the hunters related intimately to the hunt, even though this may seem, to some, too obvious or inconsequential an objective to pursue. Importantly, the alternative vantage point on the paintings of the San which is introduced here aligns itself with the spiritual thinking of the creators of the art. While it is not the intention of the authors of this paper to present a systematic critique of the leading paradigm, they feel strongly that the discussion will benefit from a dialectical engagement with the latter.

A selection of five rock art panels is first examined conventionally, i.e. in terms of the shamanistic model. The very same art works are revisited subsequently in order to explore them from an alternative, animistic perspective. It is concluded, tentatively, that the artists' visual language emphasized the significance of the narrative focus of their work, namely the various manifestations of hunter-prey sociability, the spiritual grounding of which characterized, if not defined life in traditional hunting communities across the globe.
\end{abstract}

Keywords: San, visual art, rock paintings, shamanism, hunter-prey relations

\section{Introduction}

South African scholars have contributed, significantly, to the creation of three world-class archaeological narratives. The first one relates to the re-appraisal of long established views on hominid evolution (e.g. Berger, 2000; Parkington \& Dlamini, 2015). The captivating account of the birth of complex society in the Limpopo valley, exemplified by the material remains of sites such as Schroda and Mapungubwe, is equally renowned, as are its authors (e.g. Hanisch, 2008; Huffman, 2009). Last but not least, owing to the enduring intellectual endeavours of David LewisWilliams and his co-workers at R.A.R.I. (the Rock Art Research Institute at Wits) a whole new 
understanding of prehistoric visual culture has emerged over the past few decades. This paper concerns the third narrative.

It has been estimated that some 50.000 sites south of the Zambezi contain skeletal remains and stone artefacts of the San, the earliest inhabitants of the subcontinent. The remains of their creative efforts are distributed over as many as 30.000 rock art shelters. Images of humans and animals have been portrayed in almost equal numbers. The former appeared as individuals, groups and processions. Curiously, the animal species that have been identified in the paintings only represent a fraction of the fauna that was known to the creators and consumers of the art. Both humans and animals were conventionally rendered without any clear reference to the landscape. Researchers have recorded, less commonly, paintings of tools and hunting-gathering equipment, as well as a variety of enigmatic abstract shapes, dots and flecks, ovals and other geometric forms (Garlake, 1995:11-18; Parkington, 2003:7, 8, 10, 13-14; Parkington \& Dlamini, 2015:22, 24-25, 74-77).

Supporters of the ruling theoretical orientation in the field of rock art studies, the shamanistic model, have proposed time and again that the expressive art of the San was not inspired by the hunt, in spite of the fact that hunting, as the most celebrated activity, enthused men and women alike.

Hunting had a bearing on almost every aspect of their daily lives. The same researchers have maintained, in support of their position, that hunting scenes are rarely encountered in the rock shelters and that, even when depicted, the images of hunters, hunting equipment or prey essentially constituted, in the minds of the artists, metaphorical references to "non-real" or imagined beings, places and events (e.g. Lewis-Williams, 1990:22-26; Eastwood \& Eastwood, 2006:161).

To be more precise, the mainstream practitioners conceptualized San works of art as "painted texts" the subject matter of which was expressed by a "vocabulary" of symbols and metaphors and structured by a "syntax". Significantly, its visual language was rooted in a religion which essentially revolved around a communal healing ritual known as the trance dance (LewisWilliams, 1987:166; Garlake, 1995:40-42). During the dramatic performance of the curing dance, the soul of the key participant, the shaman or healer, was believed to undertake an out-of-body journey. In his altered state of consciousness he transformed into an animal and entered into the other-worldly realm of spirits in order to gather healing potency. The paintings in the rock shelters, in essence, are the pictorial records of his hallucinatory visions (Katz, 1982; Lewis-Williams, 1987:166; Dowson \& Lewis-Williams, 1994:395).

The purpose of this paper is to invite the reader to acquaint herself with a different way of appreciating the creations of the San. It is proposed here, plainly, that the art of the prehistoric hunter was closely associated with the hunt. Admittedly, this may sound, at first, almost too selfevident to warrant any further exploration. Nonetheless, encouraged by an extensive comparative study of hunting cultures, the authors of this paper feel confident to suggest that an understanding of the art in terms of the mindset of the hunter may very well be the closest that we, as outsiders, will ever get to grasping the spiritual nature of the indigenous epistemology in which the art was framed. More to the point, it is contended that the art was firmly set in the matrix of a hunting cosmology which emphasized the common destiny of humans and animal beings and expressed, first and foremost, the intimate, spiritual bond between hunter and prey. 


\section{The art of the Shaman}

During the second half of the 1980s David Lewis-Williams and his co-workers at R.A.R.I. convincingly propagated an entirely novel understanding of San visual art. Relying heavily on Lorna Marshall's outstanding ethnographic fieldwork (e.g. 1976) among the Kalahari !Kung, and inspired by the pioneering studies of /Xam (Southern San) religion and culture by Wilhelm Bleek and his indigenous collaborators (e.g. 1911), they identified a shamanistic healing ritual, the trance dance, as the most important event in the religious practices of the San. They proposed that rock art was closely related to the trance ritual performance, and that many, if not most of the paintings depicted the healer's journey into the other world. Shamanistic healing, it was contended, "constituted the social, ritual and conceptual contexts in which the art was made" (Dowson \& Lewis-Williams, 1994:395).

Because of the hallucinatory nature of the art, acolytes of the shamanistic model soon developed a keen interest in the neurophysiology of altered states of consciousness. The latter data source proved very useful in decoding some of the more elusive images in the rock shelters, which had previously either gone unnoticed or remained unexplained. Studies investigating the somatic experience of trance (e.g. shivering, back and stomach aches, flickering vision, the sensations of flight or drowning, buzzing sounds) turned out to be exceedingly valuable when interpreting enigmatic features of the art such as mysterious creatures, abstract and geometric shapes, dots and flecks (Lewis-Williams, 1990:55-61; Lewis-Williams \& Pearce, 2005:46-59; Lewis-Williams \& Challis, 2011:77-79, 105-106, 128-129). Throughout the 1990s the shamanistic model, or trance hypothesis as it was sometimes referred to, became progressively more popular and rapidly evolved into the leading approach in rock art studies.

From the start it had been decided to abandon the four earlier approaches to rock art, the socalled narrative, aesthetic, sympathetic hunting magic and empirical perspectives (LewisWilliams, 1990:12-42, 39-41; Garlake, 1995:29-39). These were deemed to be inadequate and incompatible with the radically new ways of thinking about the art on the rock face (Lewis-Williams, 1990:3). The practitioners of the narrative approach understood the paintings to be anecdotal records of daily life or of memorable events (Lewis-Williams, 1990:22-42). The aesthetic and hunting magic vantage points originated in the $19^{\text {th }}$ century but were still popular when the shamanistic model made its debut in the 1980s. Actually, these two influential and complementary theories once provided the analytical foundation for rock art research worldwide (Lewis-Williams, 1990:4; 2002a:2, 8).

Disciples of the aesthetic school of thought emphasized the beauty of the paintings and their interpretation relied for the most part on art historical principles and methods (Lewis-Williams, 1990:12-21). Supporters of the hunting magic theory, on the other hand, perceived many of the paintings to have been used as a supernatural means, employed by prehistoric hunters, to increase the success of the hunt or to control the movements of the herds (Pager, 1975:30-8; Lewis-Williams, 2002a:2-3). Finally, the empirical perspective, modeled on the natural sciences, was designed in the 1950 s to provide a more objective, scientific and quantitative alternative to the older paradigms (Lewis-Williams, 1990:39-41).

The narrative approach was criticized for failing to recognize that San rock art was largely symbolic and that the painted images were essentially hallucinatory representations of an imaginary, "non-real" spiritual realm (Lewis-Williams, 1990:25, 26, 31, 32). The aesthetic and hunting magic perspectives, conversely, were dismissed because of their obvious bias in favour of a European frame of mind. The former was rooted in western ideas of beauty and "high art" and its art historical concepts seemed rather irrelevant. The hunting magic perspective - the brainchild of $19^{\text {th }}$ century Evolutionists -- was thought to be intensively expressive of Eurocentric 
prejudice. Not unlike the aesthetic approach, it was blamed for having "obstructed progress" in the field of rock art studies (Lewis-Williams, 1990:4, 25; Lewis-Williams, 2002a:xv, 2, 8). Finally, it was felt strongly that not much could be achieved with the empiricists' sole reliance on quantitative methods either. In their quest for an objective form of analysis they had purposely excluded the kind of data that was deemed essential to uncover the true (shamanistic) meaning of the art, namely the 'soft' cultural data pertaining to San ideology in general and to religion in particular (Lewis-Williams, 1990:39-41).

It will be argued here that analyzing the spiritual nature of the visual art of the San in terms of metaphors, mental structures and hallucinatory experience, whilst constituting a rewarding intellectual exercise in its own right, does little to grasp the indigenous ontology of its creators. It is certainly not the intention of the authors of this essay to provide the reader with an extensive critique of the shamanistic paradigm, which has, in any case, been attempted elsewhere (see Dederen \& Mokakabye, 2018). However, following the widely accepted tenet that an academic discipline will truly advance if a new perspective is created dialectically, i.e. in opposition to one or more existing vantage points (Lévi-Strauss, 1968:352; Voget, 1975:802-803), it was decided to develop and formulate the arguments that are presented here through the mediation of a critical

engagement with the mainstream paradigm. A small selection of San art works will first be analyzed using the trance hypothesis. The same paintings will then be re-examined, so to speak, 'through the eyes of the hunter'. Both types of interpretation, needless to say, are informed by an examination of the visual elements that comprise the composition of each painting/panel.

\section{Rock art as trance metaphor}

Thus far we have introduced the reader to the accepted wisdom of rock art analysis in the mainstream, without much reference to the actual paintings. We now move on to the task of illustrating that same discussion by means of a small selection of art works. The first two (see Figures 1 and 2) were traced in South Africa's most northern rock art region, the Central Limpopo Basin, more particularly in the Soutpansberg and Mapungubwe areas. The remaining ones (see Figures 3, 4 and 5) have been discovered and copied, some as far back as the 1950s, in the Drakensberg region, the Mecca of San expressive culture. Incidentally, our sample embodies two very different modes of representation. Whereas the Limpopo type imagery is known to impress many viewers on account of its near minimalist style, the more complex Drakensberg tableaux belong to an entirely different class of intriguingly detailed, polychrome creations.

The Limpopo art works basically combine two features, namely a parade like procession of women and an allusion to the animal world. In the panel from the Scot shelter (Figure 1; Eastwood, 2006:32, fig. 5D; Eastwood \& Eastwood, 2006:161), a tasseled antelope skin apron has been painted over by a succession of five human outlines. The Mapungubwe panel (Figure 2; Eastwood, 2006:32, fig. 5B; Eastwood \& Eastwood, 2006:133), on closer scrutiny, reveals that the artist has rendered the female images with kudu legs, creating a row of "antelope women". 


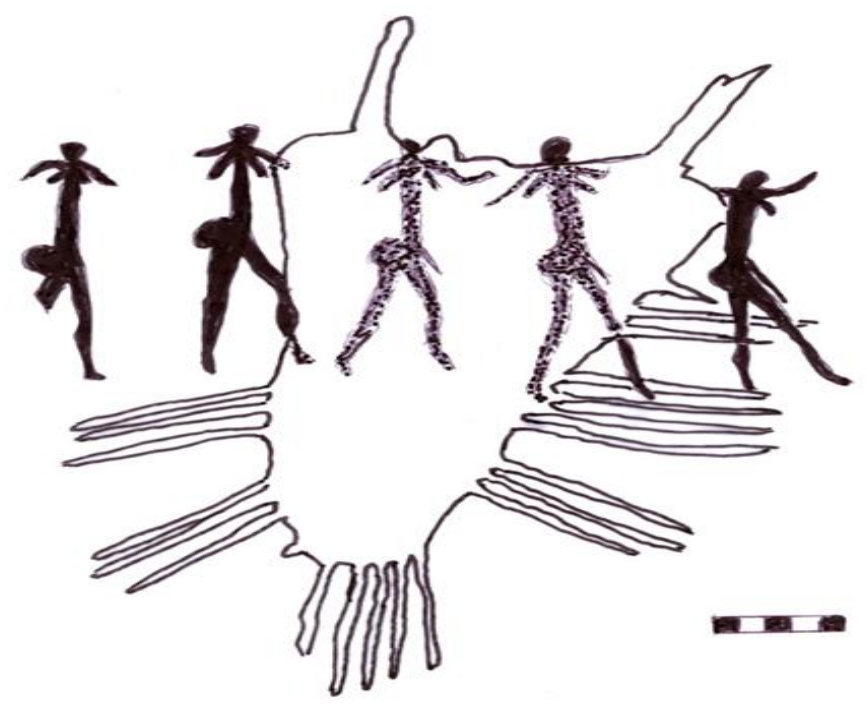

Figure 1. The Scot shelter painting (redrawn from Eastwood, 2006:32, fig. 5D).

By means of a preliminary understanding, Eastwood has argued that both panels displayed a young novice in the company of her instructors. Together they participate in a ritual initiation dance. Rites of passage among the San, as elsewhere, prepared girls for marriage and dancing constituted one of its core activities. The visual language of the painting, when elucidated by cultural data from the anthropological literature, confirmed his contention. Firstly, smaller breasts indicated the presence of a younger woman in each row of dancers. Further, in San iconography rows or processions conventionally represented dancing. Lastly, with reference to the tasseled apron, it has been reported in several ethnographic studies that a novice received a new set of aprons after she had completed her initiation. The garments symbolized the newly acquired status of womanhood and announced the girl's readiness for marriage (Eastwood, 2006:30, 31, 33).

What's more, Eastwood assumed that the meaning of the main features in the paintings would be best explored further in terms of metaphors associated with the central San healing ritual. Aligning himself with mainstream thinking, he framed the analysis of the row of dancers in both panels, the animal legs in the Mapungubwe painting and the apron depicted in the Scot shelter within a shamanistic context.

To begin with, based on the observation that the kudu was the most frequently painted animal in the rock art of the Limpopo Valley, Eastwood presumed, correctly we believe, that this particular member of the family of greater antelopes constituted the regional counterpart of the eland, the ritual animal that dominated San thought and rock art elsewhere in southern Africa. The rows of women in both panels, it was argued consequently, would have been "dancing the Kudu", i.e. they were engaged in a ceremony similar to the Eland Dance, the core event in San girls' initiation. Its performance resembled the trance dance in that it comprised a ritual of great symbolic density and transferred to the novice a form of potency similar in essence to the healing power of the male shaman (Vinnicombe, 1972:198; Eastwood, 2006:30, 33; Eastwood \& Eastwood, 2006:138139). 

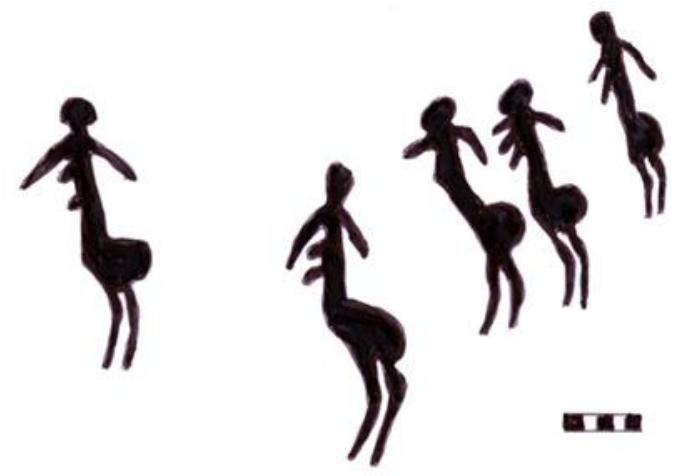

Figure 2. The Mapungubwe painting (redrawn from Eastwood, 2006:32, fig. 5B).

Next, the outlines of the so-called "antelope girl and antelope women", Eastwood suggested, could be deciphered in the very same contextual frame of the trance dance. Inspired by anthropological writing on the Eland initiation dance, he proposed that the visual blending of human and animal features in the Mapungubwe painting represented the mystical transformation of the novice. The dance allowed her to become an antelope and to "join the herd", i.e. be recognized as an adult member of the band. However, in order to achieve this, potency was required and the kudu - the "animal of passage" - was believed to have made the transformation possible, in the same way that it enabled the shaman to undertake his out-of-body journey to the other world. In brief, puberty rites engaged "powerful spiritual forces identical to those involved in trance medicine" (Eastwood, 2006:30, 31, 36; Eastwood \& Eastwood, 2006:135-136).

Finally, Eastwood contemplated whether the tasseled apron too, could be linked metaphorically to trance potency and human-animal conflation. He felt encouraged to do so, when he realized that throughout the Central Limpopo Basin aprons and kudu had been routinely painted in close proximity to the images of trance and of the medicine dance. In addition to his perceptive observations in the field, Eastwood obtained several ethnographic references supporting the assumed conceptual proximity of the healing and puberty rites. For example, he learned that some healers typically dressed in female aprons when performing curing rituals. The apron was said to symbolize the healing powers of the shaman (Eastwood, 2006:36-37; Eastwood \& Eastwood, 2006:163-167). Taken together, then, these arguments illustrate, as well as highlight, the importance of the curing ritual for the analysis of San rock art, that is, if we are to believe the mainstream interpreters. 


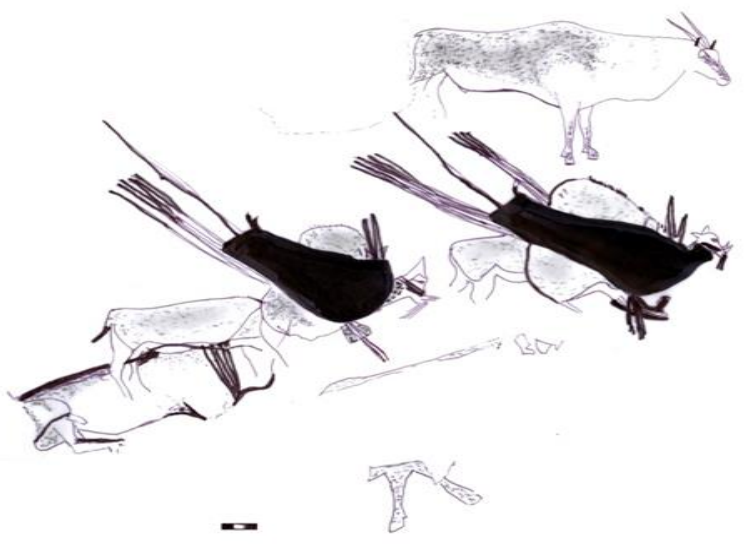

Figure 3. The Harrismith panel (redrawn from Lewis-Williams, 2015:156 fig. 7.1).

Working on the same principle, shamanistic metaphors have been deployed successfully in the process of decoding the complex art work from the Harrismith district (Figure 3; Lewis-Williams and Dowson, 1989:149 fig. 73; Lewis-Williams, 2002a:125 fig. 6.3; Lewis-Williams, 2015:156 fig. 7.1). The panel was created in three layers, possibly by several artists. The central section consisted of two curled up eland, each superimposed by the image of a mysterious creature, the body of which, on closer scrutiny, turned out to be a San hunting bag. Heads that looked partly human and partly animal had been added to these conical bags to form the creatures (LewisWilliams, 1987:173).

Members of the shamanistic school of thought have created the label "trance buck" to define creatures similar to the ones depicted in the Harrismith panel. Trance buck are said to be "hallucinatory forms". During the trance dance, the shaman merged with an antelope, often his animal assistant, in order to acquire healing power. Images of these visionary beings, it was suggested, symbolically captured the moment when a shaman fused with his potency. Moreover, trance buck were often depicted with wings, another trance metaphor, signifying the feeling of flight which shamans routinely experienced during the performance of the curing dance (LewisWilliams, 1987:174; Lewis-Williams, 2002a:124).

The eland and creature combinations had been painted over the original layer of five more eland images, aesthetically impressive portraits depicting these majestic animals in different postures: sitting, standing and walking. Each of the main elements of this panel (the seven eland and the two creatures) supposedly provided the viewer with a pictorial statement about the realm of the shaman (Lewis-Williams, 1987:172, 174).

The bleeding muzzles of the creatures have been explained as metaphors of trance too, together with the long streamers emanating from the bodies of the two sleeping eland. The former attribute marked the nasal haemorrhage endured by a shaman after he had reached the peak level of his altered state of consciousness. The streamers revealed the energy that was being gathered or harnessed by the shaman. Both the bleeding and the streamers visually suggested the presence of healing potency (Lewis-Williams, 2015:156).

More important, this particular panel has been used to introduce and define the concept of "trance dreaming" (Lewis-Williams, 1987). Trance dreaming involved a visionary activity similar in nature to the one a shaman was subjected to in trance. The two eland in hunched sleeping position, therefore, are said to portray shamans in the act of dreaming. The presence of hunting bags, together with the equipment inside and under them, perhaps indicated that the shamans were 
dreaming about a particular hunt that would take place in the nearby future (Lewis-Williams 2002a: 124, 129-130). Even the images of the five eland, on which the central scene had been superimposed, have been explained as representations of shamans (Lewis-Williams, 1987:172; Lewis-Williams, 2015:156-157).

The fourth selected art work is another superb, complex polychrome panel from the Drakensberg region, more precisely from the Game Pass in the Kamberg area; (Figure 4; Lewis-Williams, 1988:6, fig.2; 2002b:251, fig.3). It has been labeled "the Rosetta Stone of rock art" (e.g. Blundell, 2000) because its analysis, so it is said, constituted a significant moment in the development of mainstream thinking about San rock art (Lewis-Williams, 2002b:251). In the same way that the discovery of the Rosetta Stone from ancient Egypt contributed to the eventual deciphering of the enigmatic hieroglyphic script, the Kamberg panel provided the key to the art's symbolic code. Predictably by now, everything that is included in the painting, the animal as well as the four humanlike beings, have been explained in terms of the trance healing ritual.

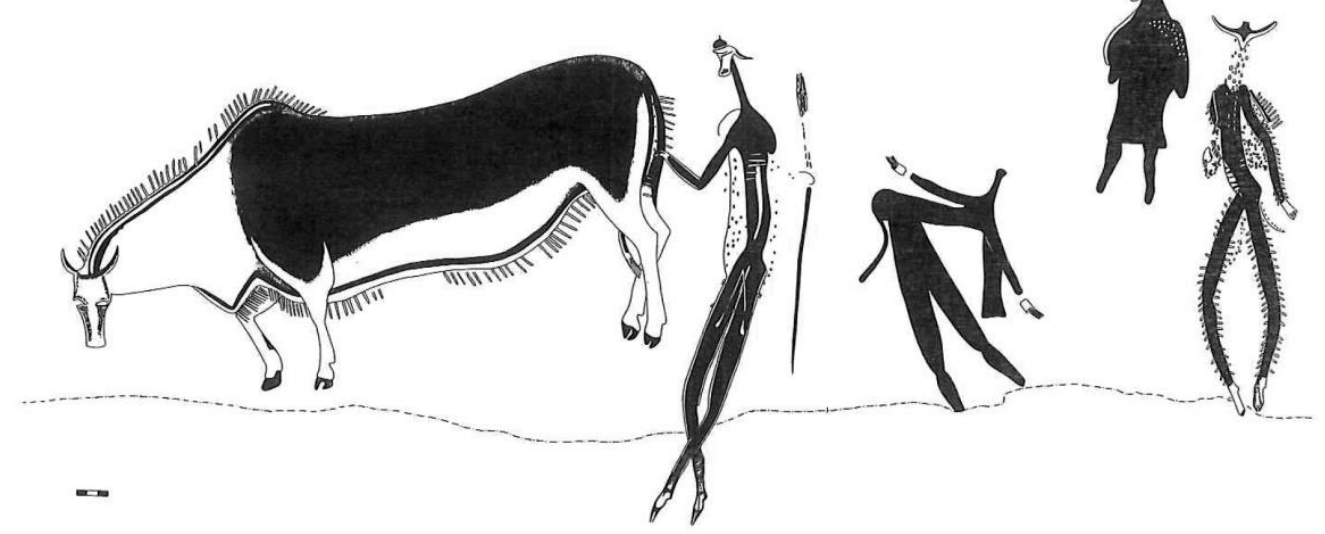

Figure 4. The Rosetta Stone of rock art (redrawn from Lewis-Williams, 1988:6, fig.2).

The viewer's attention is almost instinctively directed to towards the eland, which takes up a considerable portion of the composition. Its posture together with other details of its rendering, suggested to the interpreters that the animal was dying. Indeed, when an eland finally collapsed after being shot by poisoned arrows and chased by its pursuers, it lowered its head, raised its hair, trembled, stumbled and eventually dropped unconscious. It was noted that the crossed legs of the thin, elongated human figure on the right hand side of the eland had been painted in imitation of the crossed hind legs of the eland. What is more, the fact that the very same humanlike creature is holding the eland's tail possibly reiterated the idea, if not the importance, of its association with the eland (Lewis-Williams, 2002b:251-252).

From the start, it was felt that the meaning of the panel hinged on the observed human-animal congruence. Ethnographic descriptions of the trance dance explained its significance: in the minds of the San, the trance ritual and death were analogous, i.e. closely, metaphorically related. More specifically, when a shaman collapsed during his out-of-body journey, it was said that he was dying. The identification of the death metaphor opened the way for the uncovering of other trance metaphors and at once provided the key to the understanding of the art at large (LewisWilliams, 2002b: 252). 
It was further suggested that a second elongated creature on the extreme right of the panel had also been depicted, intentionally, in imitation of the dying eland. The body hair, standing on edge, betrayed his metaphorical death during the curing dance. A third individual, rendered in the typical bent-forward posture of trance and with stretched out arms, was identified as yet another shaman. Lastly, the fourth humanlike image too has been interpreted as a visual representation of the main protagonist of the trance or curing dance, the shaman. His large kaross, possibly made of eland skin, evidenced symbolically the human-animal transformation to which a healer was subjected at the height of his ritual performance. The hooves, tails and antelope-like heads, exhibited by all four figures, have been declared to be indicative of the very same process of shamanistic shape shifting (Lewis-Williams, 2002b:253-254). The analysis of this particular panel helped underwrite a major theoretical consideration of the shamanistic school, namely that ritual healing and painting were grounded in a similar vocabulary of trance metaphors.

\section{Through the eyes of the hunter}

To recapitulate, the paintings from the Central Limpopo Basin contain three obvious symbolic references, i.e. a human procession, "antelope women" and a tasseled apron. These signified three main elements of the healing ceremony: a ritual dance, human-animal transformation and a supernatural power which was believed to facilitate entry into the spiritual world. Further, the three layers of the Harrismith panel (the eland portraits, the hunched animals painted over them and the curious, surreal beings that seemed to emerge from the latter) clearly represent shamans and their visionary experience. Last, the Rosetta Stone panel exemplifies par excellence how the identification of trance symbolism in the art (in this particular instance the death metaphor) has made possible the decoding of San rock art. In short, each of the four selected art works can be interpreted adequately with reference to the great curing ritual, the trance dance. Or at least, so we are told by the mainstream interpreters.

No question that the analysis of the selected images in terms of the shamanistic realm has been articulated in a persuasive manner. But then, a second look at the visual language of the selected panels suggests that they could be interpreted just as easily, if not more convincingly, with reference to the spiritual bond between hunter and prey. As a matter of fact, the artists who have produced these and many other paintings in the shelters routinely combined or merged human and animal forms when creating the major protagonists in their mystical, pictorial accounts. This should not come as a surprise since human-animal relations comprised a central feature of timehonoured hunting ideologies (e.g. Guenther, 2020).

To be fair, there has never been a single, universal hunting ideology. The world-view of traditional foragers was immensely varied. Indeed, the human mind is capable of inventing and reinventing an almost endless spectrum of social and cultural arrangements. We are also aware that ethnographic data recorded in the recent past will not always accurately represent the mindset of prehistoric hunter-gatherers. The ways of the hunter, not unlike other manifestations of culture, have been subjected to acculturation and adaptation. Nevertheless, we cannot but acknowledge that hunting cultures have displayed remarkable resemblances across time and space. Based on an extensive literature review, the authors of this paper have identified sixteen shared ideological features in the cosmologies of hunters around the globe. Four of these have inspired the reinterpretation of the selected art works.

We contend that the visual elements of both panels from the Central Limpopo Basin essentially embodied the concept of Animal Power. The notion of a spiritual force innate in animal beings has been admirably explored in The Power of Animals (Morris, 2000), one of the rare monographs dedicated to the study of the cosmology of hunting societies. Traditional hunters, universally, regarded this power as potentially destructive or helpful. Indeed, animals could cause harm or 
promote well-being. Supernatural potency, which was located in the blood, internal organs, skin and certain body parts such as the head, horns or tail (e.g. Gottlieb, 1989:493; Morris, 2000: 104108), constituted the soul or life essence of an animal being. A similar force, although less intense, was believed to reside within the human body (e.g. Douglas, 1975:29; James, 1990:201-202; Low, 2007).

It is essential to emphasize from the onset of our analysis that in the mystical world-view of the hunter, the antelope was more than just a metaphor. The hunters perceived the kudu to be a powerful spiritual creature that routinely intervened in community life and contributed to the survival of its members. Unsurprisingly, then, it also played an important role in the rites of passage of both sexes. Its potency was needed to facilitate the physical and spiritual growth of the youths of both sexes into full members of society. Animal Power mediated the mystical process through which adolescents acquired male prowess and women's fertility (Guenther, 1999:164-179; Keeney \& Keeney, 2013).

Informed by the mindset of the hunter, the images of female bodies merging with kudu spirits, in the Mapungubwe panel, can be explained as a visual disclosure of the spiritual affinity or bond between humans and animals that characterized and determined much of the existence of hunting communities across the globe. Because the kudu was deemed capable of activating and guarding the novice's life-generating powers, the Kudu Dance itself served as a ritual means to honour and to celebrate this sacred animal. Rites of passage, in addition, provided a ceremonial opportunity to call upon its Power. Along similar lines of thought, the image of the tasseled apron in the Scot shelter must not be viewed as a mere symbol for the newly acquired status of womanhood. The icon of the apron reminded viewers that Animal Power was manifestly present during the rites and effectively braced a young woman's life-giving powers.

We feel confident to state that the trance curing ritual and its metaphors do not hold the key to a better comprehension of the C.L.B. panels. Indeed, these two paintings demonstrate convincingly that not all rock art did "arise out of the experiences of the shaman" (Lewis-Williams, 1990:75). Truly, one does not need trance potency to appreciate the role and significance of Kudu Power in the transformative process of girls' initiation rites. From a native point of view the opposite seems the case, since trance healing potency was just one of many manifestations of a vital force that was perceived to exist throughout the cosmos. If anything, the concept of Animal Power, and more particularly the wider animistic religion in which it was grounded, should improve our understanding of the curing ritual. In other words, and essentially, the idiom of the hunt does not offer much support for the pressing of San initiatory ritual and dance into the shamanistic analytical mould.

As for Eastwood's submission that "the animals in the paintings are behaving like people" (2006:26), we consider such a statement equally expressive of an outsider's perspective. The world-view of traditional hunter-gatherers was theriocentric rather than anthropocentric. That is to say, humanity modeled itself on the animal world. Women and men alike were constantly being inspired and guided by animals. In their everyday thoughts and actions, people behaved like animal beings.

Moving on to the Harrismith panel, we feel strongly that its composition, meaning and function are fundamentally built around the idea of a Cosmic Unity. In the eyes of the hunter, we learned during our comparative study, different modes of being, types of beings and the realms they inhabit, were not just intertwined and interactive, they were mutually interdependent. In our own western or modern world-view humans and animals are conceived, in principle at least, as opposed and separate categories. Conversely, in the ontology of traditional hunters, animals were perceived to be conscious and intelligent members of the same cosmos they shared with humans. Animal- 
persons engaged routinely in social relations with humanity and needed to be respected in order to safeguard the survival of hunter and prey alike (e.g. Nadasdy 2007).

Of further interest to the analysis of the Harrismith panel is the related belief that life and death too constituted integrated rather than opposed existential entities. In the understanding of the hunter, killing a prey animal, paradoxically, was believed to promote the continuity of the species. The evolutionist Frazer has illustrated and explored this particular aspect of the animistic worldview in admirable detail in a separate chapter of his opus major The Golden Bough (1922:499517; see also e.g. Herbert, 1993:221, 238; Morris, 2000:113).

Let us revisit the central component of the panel. Contrary to the mainstream interpretation, the two curled up eland are, at least in our opinion, not sleeping. They have been killed in the hunt. However, in the animistic world-view the killing of these animals did not result in the termination of their existence. Their souls have joined the realm of spirits. They will monitor the herd. They will maintain the supply of animals to the hunters by guiding them towards the prey or by magically fortifying their hunting equipment.

Perhaps, then, the two mysterious creatures could be visual representations of the eland spirits? Our reading is supported by the fact that the shape of the two hunting bags closely resembles the way in which eland torsos were conventionally rendered. On the other hand, the presence of unstrung bows and other objects, inside and under the bags/spirits, probably illustrates that Eland Power is being transferred to them. By strengthening the hunting tools, the animal spirits have enhanced the chances of a successful hunt.

Finally, the five eland portraits, on which the images of dead eland and their souls have been superimposed, depict a third category of eland, namely the living animals. These exquisite images, evidently the products of a labour of love, expressed the admiration for the animals as well as the hunter's yearning for a future quality catch. Otherwise said, the act of painting itself could have been a ritual means at replacing the killed animals (see also Vinnicombe, 1976: 172173). By combining the living, dead and spiritual eland in one panel, the artist possibly intended to illustrate, explain and endorse the notions of a Cosmic Unity between humans and their animal kin.

There is no need to involve shamanistic beliefs or trance metaphors in the interpretation of the Rosetta Stone panel either. It makes perfect sense in terms of the world-view of hunting societies, more particularly with reference to the concepts of the Master of the Animals and the Contract between hunter and prey. In the animistic ontology, prey animals were controlled by a great spiritual being - the Master of the Animals or Game Keeper - who could either release or withhold them. When an animal was killed, its soul would inform the Master about its treatment by the hunters. The Master could also sent spiritual helpers to inspect the condition of the hunted animals (e.g. Paulson \& Auer, 1964; Guenther, 1999:63,111; Hoff, 2011).

What is more, hunting in traditional society, in shrill contrast to modern perceptions and practice, was deemed to be a holy occupation, a form of ordained killing. The interaction between hunter and prey was regulated by a spiritual agreement or Contract. Male youths had first been acquainted with the notion of balanced hunter-prey relations through the didactic efforts of storytellers. Subsequently, during their rites of passage into manhood, the young hunters expanded their knowledge and understanding of the Contract, when being introduced to the relevant taboos and to the rules of engagement with prey animals (Martin, 1978:113-120; Martin, 1981; Knight, 2012:237-239). Could the Rosetta Stone panel perhaps have served a similar didactic purpose? 
Let us return to the paintings. We concur with previous interpreters that all four humanlike creatures are visually associated with the dying eland by touching it, mimicking its posture or exhibiting its body features and sensations. One figure holds the animal's tail; another bends forward and stumbles; several display antelope hooves, muzzles, ears and horns or wear antelope coats. Clearly, the notion of human-animal affinity played an important role in the visual design of this painting. However, the mainstream interpreters, surprisingly, have failed to notice or explain the obvious fact that not less than three different types of figures can be identified in this art work. Surely, the artist intended the formal disparities in his rendering of the humanlike outlines to be meaningful?

If truth be told, only the two thin, elongated figures, situated on the left and right of the panel, are similar in form. There is a dividing line in the middle of the chest and horizontal lines where the ribcage is located. The lower limbs, which appear to be dislocated, have been painted as more or less lifeless appendages to the upper body. The forward bending figure differs visibly from the two elongated ones. He has been painted following the San canon of body proportions and anatomical details, displaying muscular legs, pronounced buttocks, widening torso etc. (see e.g. Garlake, 1995:20-24). His appearance is the most humanlike of the four. The shape of the remaining image type is dominated by the outline of his large coat or kaross. Similar kaross-clad figures have been recorded elsewhere in the rock art of the Drakensberg. He is smaller and seems to be inactive apart from perhaps observing the others.

Moreover, previous analytical accounts have failed to shed light on the fact that the eland and the two long and slender images are facing the viewer, whilst the remaining ones are not. This is certainly an unusual feature, as heads are conventionally depicted in profile. The kaross-clad figure glances towards the left side of the panel, maybe in the direction of the eland? The small, featureless head of the individual in bending forward posture is facing neither the viewer, nor any of the other images in the painting.

What are we to make from these observations when we attempt to examine them against the backdrop of the mindset of the hunter? Let us initiate our visual analysis with a second, closer look at the two elongated figures. Vinnicombe routinely encountered similar images throughout the research area of her doctoral studies. Some appeared to be walking or moving about with crossed legs, as does the creature holding the eland's tail in this panel. Based on the fact that the crossed-legged body posture was associated in Khoisan culture with death and burial, Vinnicombe has argued, convincingly, that this image type was meant to depict the spirits of the dead (Vinnicombe, 1976:322-325; see also Solomon, 2008).

The artist, conceivably, has portrayed two spirits of the dead - ancestral hunters is probably a more appropriate term - who have come to inspect the dying eland in order to establish if it has not been ill-treated by the hunters and if all forms of ritual behavior, as prescribed by custom (the Contract), have been observed. They have been sent by the Master of the Animals who stands behind or nearby them, looking upon his favourite creation, the eland. The formal details of the ancestral hunters visually express, first and foremost, their empathy with the animal.

The same idea of human-animal affinity seems to characterize the hunter who bends forward. He is mimicking the stumbling, dying eland, maybe as part of a prescribed hunting ritual (e.g. Pager, 1982). All three men are grieving. The death of the animal was perceived to be a necessary evil. The eland and the ancestral hunters face the viewers of the painting as if to address and remind them that both individual and communal welfare depend on the respectful behaviour of humans towards their animal kin. 


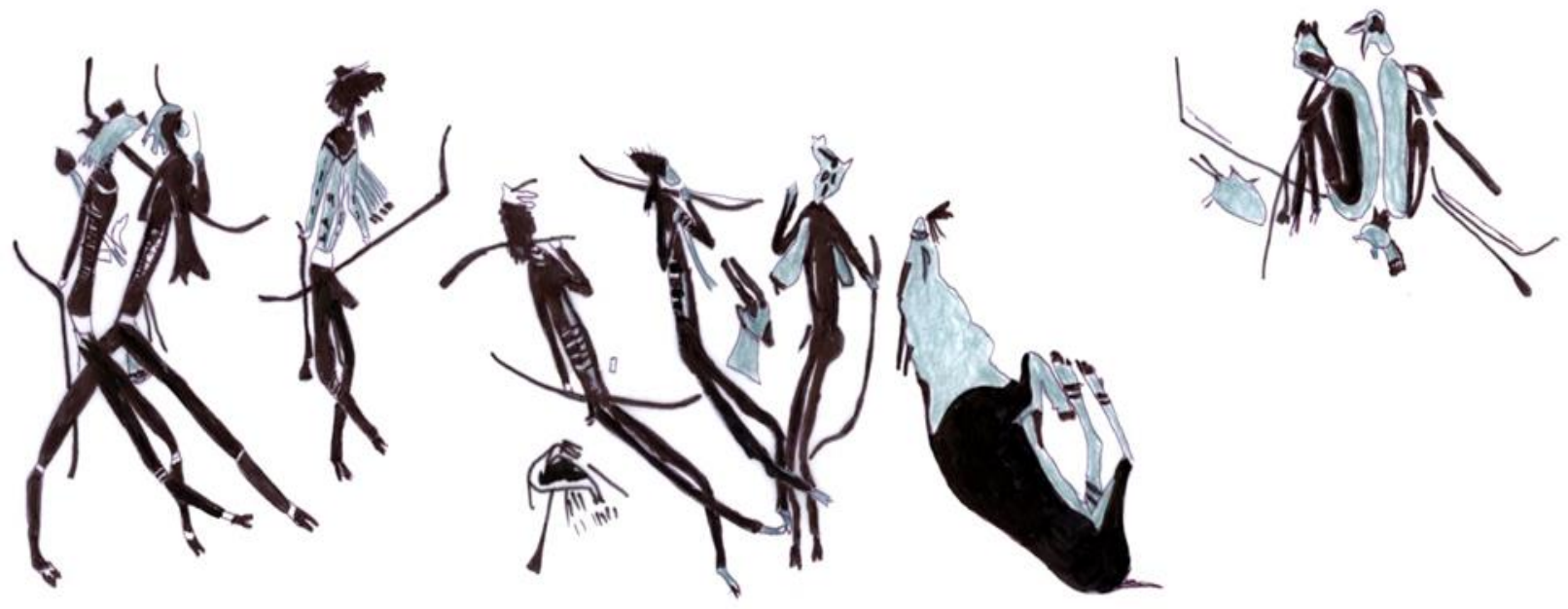

Figure 5. The Qacha's nek panel (redrawn from Vinnicombe, 1976:175).

We came across similar visual clues betraying the artist's source of inspiration (the idiom of the hunt) in another complex rock art panel from the Drakensberg (see Figure 5; Vinnicombe, 1976:175), recorded and superbly traced by Vinnicombe in the Qacha's nek district during the 1950s. In her view, the painting is composed of a tied up eland and eight of the split-body figures. The latter are defined as spirits of the magical specialists who controlled the movement of prey animals, the so-called game sorcerers (Vinnicombe, 1976:322, 324-326, 332). We mentioned during the discussion of the Rosetta stone panel that, in the mainstream interpretation, this type of image has been accounted for as a symbolic representation of the shaman. The elongated body, awkward posture and hooves supposedly indicated to the viewer, metaphorically, that the healer was shape-shifting into an antelope (Lewis-Williams, 2002b:251-252).

In the same way as the mainstream analysis failed to, conclusively, explain why not less than four shamans needed to be present in close proximity to the dying eland in the Rosetta stone panel, Vinnicombe did not specify what purpose was served by eight spirits of game shamans gathering around a tied up animal, or, for that matter, why the animal was tied up in the first place. More importantly, she seemed to have overlooked the fact that the seated figures on the extreme right of the panel are not of the split body type. Perhaps the presence of hunters around a dead eland can be divided into three groups? Six spirits of the dead have come to examine the dead eland. While the three individuals in the middle of the composition appear to be engaged in a discussion, the remaining three have only just arrived and are about to join the inspection of the eland.

In terms of the world-view of the hunter, these ancestral hunters have come to assure themselves that their descendants have not deviated from the hunting rules. The two men on the extreme right are the hunters who have tracked down and killed the wounded eland. They are resting and waiting for others to catch up with them. They seem unaware of the spiritual beings on their left. Intriguingly, their affinity with the dead animal is manifested by some of their features (antelope hooves and ears) and by their body pose, which could very well mimic the posture of the dead eland. Finally, there is the eland head, which has escaped the attention of previous analysts too. We suggest that the head confirms both the presence and importance of Animal Power in the conceptual makeup of the panel. Was it meant to remind the hunters that a prescribed ritual 
needed to be performed during or after the cutting up of the prey? Pager (1982) has explored the ethnographic and painted evidence for the existence of such a ritual among the San.

\section{Some concluding thoughts}

No doubt, the design of the shamanistic model aimed at attributing meaning to San rock art "through the eyes of the San". It was intended by its founders to replace the "debilitating misunderstandings" of Western observers on which the older approaches were built. It was hoped that the new paradigm would provide an "interpretative" explanation of San visual culture, deeply rooted in the religious beliefs of its creators and expressed in their own thought categories and idioms (e.g. Lewis-Williams, 1990:34-39, 44; Lewis-Williams \& Challis, 2011:10-14, 189-192). But has the ruling theory of rock art studies really succeeded to live up to its gallant intentions? We think not. The trance hypothesis, candidly speaking, is yet another well-intended and astute anthropological, culture-sensitive approach to hunter-gatherer existence, essentially conceived in western ways of viewing the world.

The reason for the failure to generate an insider's understanding of the artistic creations of the San is not far to seek. With regards to its epistemology, the shamanistic model has drawn heavily on semiotics and structuralism, two paradigms which, in anthropological circles as elsewhere, are not particularly remembered, let alone celebrated, for having stimulated an indigenous understanding of culture (e.g. Clifford \& Marcus, 1986). Phenomenology, in this regard, would certainly have been a wiser and more rewarding choice of inspiration, as is clearly manifested by the insightful contemplations of Thomas Dowson (2007) and Ann Solomon (2011), who have probed the visual art of the San for elements of an underlying native epistemology.

We have mentioned earlier on that mainstream interpreters have passionately directed their energy towards the decoding of various religious metaphors. In their quest for an improved understanding of the visionary or hallucinatory elements in the art works, the same researchers have eagerly looked for answers in the neurophysiology of the human brain. Neither of these intellectual infatuations - which were perceived to "complement each other in giving a better understanding of southern African rock art" (Lewis-Williams, 1990:62) - has been conducive to the task of elucidating the "Sanness" of the paintings.

Truly speaking, to define spirituality or religion as "a way of coming to terms with the electrochemical functioning of the brain" (Lewis-Williams \& Pearce, 2004:xxiv), or to suggest that it is impossible to discuss religion or cosmology "without recognizing the input of the human nervous system" (Lewis-Williams \& Pearce, 2005:41) clearly betrays an outsider's view. However, far from campaigning for the abandonment of the shamanistic model, the authors of this paper merely wish to emphasize that attempting to read San rock art through the eyes of the hunter is probably the best that we, as outsiders, can do in order to achieve an indigenous understanding.

There was little in the daily life and mind of traditional foragers that was not shaped, influenced or inspired by their close affinity with nature at large and with animal beings in particular. Only if we sincerely try to grasp the ways in which hunters used to live, talk and think animals, in addition to killing and eating them, will a world-view rooted in the permeability or holistic essence of human and animal existence become more intelligible to us. For that reason we have endeavoured in this paper, be it in a very elementary fashion, to analyze a small sample of art works against the backdrop of some of the ideological features of hunter-gatherers across the globe. In the understanding of traditional hunters, animals were expected to guide humans and shape their life, to regulate ritual behaviour, to influence health and well-being, to buttress female and male identity, to safeguard human fertility and survival, to determine their destiny; in sum: to enable humans to make sense of their existence. 


\section{References}

Berger, L.R. \& Hilton-Barber, B. (2000). In the Footsteps of Eve. The Mystery of Human Origins. National Geographic. Adventure Press.

Bleek, W. (1911). Specimens of Bushman Folklore. London: George Allen.

Blundell, G. (2000). African rock art: Game Pass. Heilbrunn Timeline of Art History. Metropolitan Museum of Art.

Clifford, J. \& Marcus, G.E. (1986). Writing Culture: The Poetics and Politics of Ethnography. Los Angeles: University of California Press.

Dederen, J.-M. \& Mokakabye, J. (2018). Monologue and multivocality in San rock art studies. Acta Academica, 50(1), 40-61.

Douglas, M. (1975). Implicit Meanings. London: Routledge.

Dowson, T.A. (2007). Debating shamanism in southern African rock art: Time to move on... South African Archaeological Bulletin, 62, 49-61.

Dowson, T. A. \& Lewis-Williams, J. D. (1994). Contested Images: Diversity in Southern African Rock Art Research. Johannesburg: Witwatersrand University Press.

Eastwood, E. B. (2006). Animals behaving like people: San rock paintings of kudu in the Central Limpopo Basin, southern Africa. South African Archaeological Bulletin, 61, 26-39.

Eastwood, E. \& Eastwood, C. (2006). Capturing the Spoor. An Exploration of Southern African Rock Art. Cape Town: David Philip.

Frazer, J. (1922) The Golden Bough. A Study in Religion and Magic. London: Macmillan.

Garlake, P. (1995). The Hunter's Vision. The Prehistoric Art of Zimbabwe. London: British Museum Press.

Gottlieb, A. (1989). Hyenas and heteroglossia: myth and ritual among the Beng of Côte d'Ivoire. American Ethnologist, 16, 487-501.

Guenther, M. G. (1999). Tricksters and Trancers: Bushman Religion and Society. Bloomington: Indiana University Press.

Guenther, M. G. (2020). Human-Animal Relationships in San and Hunter-Gatherer Cosmology. Palgrave: Macmillan.

Hanisch, E.O.M. (2008). Schroda: the archaeological evidence, in, Van Schalkwyk, J.A. and Hanisch, E.O.M. (eds), Sculptured in Clay. Iron Age Figurines from Schroda, Limpopo Province, South Africa. Pretoria: National Cultural History Museum, 21-38.

Herbert, E. W. (1993). Iron, Gender and Power. Rituals of Transformation in African Societies. Bloomington: Indiana University Press.

Hoff, A. (2011). Guardians of nature among the /Xam San: an exploratory study. South African Archaeological Bulletin, 66, 41-50. 
Huffman,T. (2009). Mapungubwe and Great Zimbabwe: The origin and spread of social complexity in southern Africa. Journal of Anthropological Archaeology, 28, 37-54.

James, W. (1990). Antelope as self-image among the Uduk in, Willis, R. (ed.), Signifying Animals. Human Meaning in the Natural World. London: Routledge, 196-203.

Katz, R. (1982). Boiling Energy. Community Healing Among the Kalahari San. Cambridge: Harvard University Press.

Keeney, B. \& Keeney, H. (2013). Reentry into first creation: a contextual frame for JU/'hoan Bushman performance of puberty rites, storytelling, and healing dance. Journal of Anthropological Research, 69(1), 65-86.

Knight, J. (2012). The anonymity of the hunt. A critique of hunting as sharing. Current Anthropology, 53, 334-355.

Lévi-Strauss, C. (1968). The concept of primitiveness, in, Lee, R. B. and De Vore, I. (eds), Man the Hunter. Chicago: Aldine, 349-352.

Lewis-Williams, D. (1990). Discovering Southern African Rock Art. Cape Town: David Philip.

Lewis-Williams, D. \& Dowson, T. (1989). Images of Power. Understanding Bushman Rock Art. Cape Town: Southern Book publishers.

Lewis-Williams, D. \& Pearce, D. (2005). Inside the Neolithic Mind. London: Thames and Hudson.

Lewis-Williams, D. \& Pearce, D. (2004). San Spirituality. Cape Town: Double Storey, Juta.

Lewis-Williams, D. \& Challis, S. (2011). Deciphering Ancient Minds. The Mystery of San Bushman Rock Art. London: Thames and Hudson.

Lewis-Williams, J. D. (1987). A dream of eland: an unexplored component of San shamanism and rock art. World Archaeology, 19(2), 165-177.

Lewis- Williams, J. D. (1988). The world of man and the world of spirit: An interpretation of the Linton rock paintings. Margaret Shaw Lecture 2. Cape Town: South African Museum.

Lewis-Williams, J. D. (2002a). A Cosmos in Stone. Interpreting Religion and Society through Rock Art. Walnut Creek: Alta Mira Press.

Lewis-Williams, J. D. (2002a). A dream of eland, in, Lewis-Williams, J. D., A Cosmos in Stone. Interpreting Religion and Society through Rock Art. Walnut Creek: Altamira Press, 119-131.

Lewis-Williams, J. D. (2002b). Three-dimensional puzzles: southern African and Upper Palaeolithic rock art. Ethnos, 66(2), 245-264.

Lewis-Williams, J. D. (2015). Myth and Meaning. San-Bushman Folklore in Global Context. Cape Town: U.C.T. Press.

Low, C. (2007). Khoisan wind: hunting and healing. The Journal of the Royal Anthropological Institute, 13, 571-590.

Marshall, L. (1976). The !Kung of Nyae Nyae. Cambridge MA: Harvard University Press. 
Martin, C. (1978). Keepers of the Game: Indian-Animal Relationships and the Fur Trade. Berkeley: University of California Press.

Martin, C. (1981). The American Indian as miscast ecologist. The history teacher, 14, 243-252.

Nadasdy, P. (2007). The gift in the animal: the ontology of hunting and human-animal sociality. American Ethnologist, 34, 25-43.

Morris, B. (2000). The Power of Animals: An Ethnography. Oxford: Berg.

Pager, H. (1975). Stone Age Myth and Magic. Graz: Akademische Druck.

Pager, H. (1982). The ritual hunt: parallels between ethnological and archaeological data. South African Archaeological Bulletin, 38, 80-87.

Parkington, J. (2003). Cederberg Rock Paintings. Cape Town: Creda.

Parkington, J. \& Dlamini, N. (2015). First People. Ancestors of the San. Cape Town: Creda.

Paulson, I. \& Auer, N. (1964). The animal guardian: a critical and synthetic review. History of Religions, 3, 202-219.

Solomon, A. (2008). Myths, making, and consciousness: differences and dynamics in San rock art. Current Anthropology, 49(1), 59-86.

Solomon, A. (2011). Writing San histories: the '/Xam' and 'Shamanism' revisited. Journal of Southern African Studies, 37, 99-117.

Voget, F. W. (1975). A History of Ethnology. New York: Holt, Rinehart and Winston.

Vinnicombe, P. (1972). Myth, Motive, and Selection in Southern African Rock Art

Africa. Journal of the International African Institute, 42(3), 192-204.

Vinnicombe, P. (1976). People of the Eland. Rock Paintings of the Drakensberg. Pietermaritzburg, University of Natal Press. 